University of Nebraska - Lincoln

DigitalCommons@University of Nebraska - Lincoln

May 1998

\title{
"Other Teens Drink, But Not My Kid": Does Parental Awareness of Adolescent Alcohol Use Protect Adolescents from Risky Consequences?
}

\author{
Karen Bogenschneider \\ University of Wisconsin-Madison, kpbogens@wisc.edu \\ Ming-Yeh Wu \\ Soochow University, mwu@mbm1.scu.edu.tw \\ Marcela Raffaelli \\ University of Nebraska-Lincoln, mraffaelli1@unl.edu \\ Jenner C. Tsay \\ University of Wisconsin
}

Follow this and additional works at: https://digitalcommons.unl.edu/psychfacpub

Part of the Psychiatry and Psychology Commons

\begin{abstract}
Bogenschneider, Karen; Wu, Ming-Yeh; Raffaelli, Marcela; and Tsay, Jenner C., "'Other Teens Drink, But Not My Kid": Does Parental Awareness of Adolescent Alcohol Use Protect Adolescents from Risky Consequences?" (1998). Faculty Publications, Department of Psychology. 116.

https://digitalcommons.unl.edu/psychfacpub/116
\end{abstract}

This Article is brought to you for free and open access by the Psychology, Department of at DigitalCommons@University of Nebraska - Lincoln. It has been accepted for inclusion in Faculty Publications, Department of Psychology by an authorized administrator of DigitalCommons@University of Nebraska - Lincoln. 
Published in Journal of Marriage and the Family 60 (May 1998): 356-373. http://www.blackwellpublishing.com/journal.asp?ref=0022-2445

Copyright (C 1998 National Council of Family Relations; published by Blackwell Publishing. Used by permission.

\title{
"Other Teens Drink, But Not My Kid": Does Parental Awareness of Adolescent Alcohol Use Protect Adolescents from Risky Consequences?
}

\author{
KAREN BOGENSCHNEIDER University of Wisconsin \\ MING-YEH WU Soochow University \\ MARCELA RAFFAELLI University of Nebraska-Lincoln \\ JENNER C. TSAY University of Wisconsin
}

\begin{abstract}
This study included 199 White mother-adolescent dyads and 144 White father-adolescent dyads. All adolescents reported regular alcohol use, yet less than one third of parents were aware of their adolescents' drinking. Parental awareness of adolescent alcohol use served to protect adolescents by moderating the relation of parents' responsiveness to episodes of drinking and driving. Aware parents were more likely than unaware parents to believe their adolescents' close friends drank alcohol. Aware mothers worried more about their adolescents' risk behaviors and discussed them more frequently with their adolescents. Aware fathers held values less disapproving of adolescent alcohol use and were less apt to perceive their community as supportive.
\end{abstract}

Key Words: adolescents, alcohol use, parenting

Despite public concern and media hype surrounding drug use by adolescents, studies have confirmed that American adolescents' use of some illicit drugs, includ- ing cocaine, hallucinogens, and heroin, is minimal. In a 1995 national survey, only from $1 \%$ to $4 \%$ of eighth, 10 th, and 12th graders reported using any of these substances in the previous 30 days. The use of other substances during the month preceding the study was more prevalent, with from $9 \%$ to $21 \%$ of students reporting marijuana use and from $19 \%$ to $34 \%$ reporting cigarette use. Alcohol use was even higher, with $25 \%$ of eighth graders, $39 \%$ of 10 th graders, and $51 \%$ of 12 th graders reporting that they drank in the previous month (Johnston, O'Malley, \& Bachman, 1996). Public attention has been misdirected at adolescents' use of illicit drugs, even though licit drugs, such as alcohol and tobacco, cause more deaths in the United States than all other drugs combined (Ellickson, 1992) and may, in the long run, pose a greater risk to the developing adolescent and more harm to society (Kandel, Single, \& Kessler, 1976; Newcomb \& Bentler, 1989).

Clearly, the drug of choice among adolescents, even those in early adolescence, is alcohol (Kandel et al., 
1976; Smart, Chibucos, \& Didier, 1990). Alcohol use by adolescents jeopardizes their development. For example, alcohol use often occurs with other risky behaviors, such as delinquency, unprotected sexual activity, and dropping out of school (Hawkins, Catalano, \& Miller, 1992; Levy, Lampman, Handler, Flay, \& Weeks. 1993). Moreover, when use begins before age 15 , adolescents increase their risk of later drug dependency by 6-10 times (Robins \& Przybeck, 1987). Alcohol use also has been implicated in accidental injuries and death (Hawkins et al., 1992; Higgins, 1988; Irwin \& Millstein, 1986). Motor vehicle crashes are a leading cause of disability and death among adolescents and young adults In 1994 alcohol was involved in $29 \%$ of motor vehicle deaths of $15-$ to 17 -year-olds and in $44 \%$ of deaths of 18 - to 20 -yearolds (US. Department of Health and Human Services, 1995a, 1995b).

Because alcohol use is normative for many adolescents, youth must acquire values, motives, skills, and habits for avoiding negative consequences (Maccoby, 1992) when using alcohol. Parenting practices have proven to be critical influences on adolescents' decisions about alcohol use (Barnes \& Farrell, 1992; Barnes, Farrell, \& Banerjee, 1994; Kandel, 1986; Patterson, De Baryshe, \& Ramsey, 1989; Simons, Conger, \& Whitbeck, 1988), even more important than parents' own use of drugs (Brook, Whiteman, Gordon, \& Cohen, 1986b; Kandel \& Andrews, 1987). During adolescence, parents' attempts to control adolescents' behavior should not be abandoned or applied arbitrarily (Maccoby \& Martin, 1983) but transformed into explanation. discussion, and negotiation.

One dimension of parents' management practices - their awareness of adolescent alcohol use - has received surprisingly little empirical attention, despite its pragmatic salience to practitioners involved in alcohol prevention efforts and its consistency with theoretical explanations of parenting behavior. From a pragmatic perspective, we propose that parental awareness of alcohol use may be fundamental to effective management because parental response, or lack thereof, may be determined, at least in part, by parents' knowledge of their adolescents' behavior (Patterson, 1975, 1986; Patterson, Reid, \& Dishion, 1992). From a theoretical perspective, we argue that the study of adolescent alcohol use is an important window into parent-adolescent relationships because alcohol use is, for many adolescents. an arena where issues of autonomy and independence are played out (Baumrind, 1987; Irwin \& Millstein, 1986) We examine three questions (a) whether parents are aware that their adolescents and their adolescents' close friends drink alcohol, (b) whether parental awareness matters, specifically whether it moderates the influence of other parent and peer variables in averting risky consequences of adolescent alcohol use, and (c) what parent, adolescent, and community factors influence the likelihood that parents are aware that their adolescents use alcohol. We begin with an empirical and theoretical rationale for examining parental awareness of adolescent alcohol use. We discuss how this study overcomes shortcomings of previous research and then present our hypotheses

\section{Empirical Parental Bases for Studying Awareness of Adolescent Use of Alcohol}

Parents' denial of their adolescents' drug use is one characteristic of families with adolescent drug abusers (Reilly, 1976), yet few studies have examined parental awareness of adolescents' alcohol use, especially among high school students. In most studies, including our pilot studies, parent and child reports were positively but weakly correlated, with the majority of parents underestimating the likelihood that their own children were using alcohol (Bogenschneider, Tsay, \& Wu, 1996; Dielman, Leech, \& Loveland-Cherry, 1995; Ross, Leech, \& Loveland-Cherry, 1997).

Langhinrichsen and colleagues (1990), however, reported that parents were equally likely to overestimate drinking behavior, a rare occurrence in our pilot studies. These divergent findings are explained by a difference in the conceptualization of adolescent alcohol use. Our pilot studies examined parents' awareness of whether their adolescents were currently using alcohol, but Langhinrichsen and colleagues measured whether adolescents had ever used alcohol. Thus, parents who overestimated their adolescents' use were primarily those who reported that the adolescent had used alcohol once or twice, whereas the adolescent reported never using it.

\section{Theoretical Rationale for Studying Parental Awareness of Adolescent Alcohol Use}

For many adolescents, the developmental changes of adolescence - testing limits, experimenting with ways of becoming more independent, and assuming more autonomy in decision making — are manifested through alcohol use (Baumrind, 1987; Irwin \& Millstein, 
1986). Parental awareness of adolescent alcohol use may inform our theoretical understanding of the transformation of the parent-child relationship during adolescence. A full understanding of childrearing may require relying on two theories, one at a macrosocial level to describe the larger context (e.g., parenting values and the emotional climate) of the parent-adolescent relationship (Darling \& Steinberg, 1993) and the other at a microsocial level to explain the specific pathways through which parents influence adolescent development (Maccoby, 1992; Patterson et al., 1992). Macrotheories recently have shifted from an emphasis on adolescent detachment (Freud, 1958) or individuation (Blos, 1979) from parents to a focus on how individuation occurs optimally when adolescents maintain close and continuing relationships with parents (Cooper \& Cooper, 1992; Steinberg, 1990; Youniss \& Smollar, 1985). According to individuation-connectedness theory, if the parent-child relationship transforms from one based on unilateral authority to one of interdependence and cooperative negotiation, adolescents still seek their parents' advice, which allows continued parental guidance over their offspring's development.

Microtheories of development, such as social learning theory (Bandura, 1977), explain how parents can influence the increasingly autonomous adolescent. Although the initial experiments that led to social learning theory did not involve parents, the concepts were intended to explain parents' attempts to socialize their children (Maccoby, 1984) and resulted in the predominant set of constructs for studying childrearing (Maccoby \& Martin. 1983). Although social learning theory deals with the mechanisms through which parents and children reciprocally influence each other (Patterson, 1975; Patterson \& Gullion, 1968), this study focuses primarily on parental behavior, specifically attempts to influence or change adolescent behaviors related to the risky use of alcohol. We draw on the work of Bandura, who studied adolescence and incorporated a cognitive component into social learning theory by applying its principles to observational processes (Bandura, 1977; Conger, 1976; Muuss, 1988).

Based on Bandura's theorizing, social learning is posited to occur through four processes - attention, retention, motor reproduction, and motivation - the first of which is of primary interest in this study. Much social learning is thought to occur through attention to or observation of the behavior of others in everyday situations. The first steps in changing behaviors are said to be observation and data collection (Patterson, 1975). That is, parents can respond appropriately only to behaviors they are aware of. Although empirical studies are not definitive, the evidence suggests that awareness is a prerequisite for contingent responses (Bandura, 1977). For example, in studies of child deviance and antisocial behavior (Blechman, 1980; Patterson et al., 1992), parents were able to change a child's behavior only if they were first aware of it (Patterson \& Gullion, 1968).

\section{Conceptualization of Parenting \\ Influences on Parental Awareness of Adolescent Alcohol Use}

Due to the absence of studies on correlates of parental awareness of adolescent alcohol use, the hypotheses in this study were guided by empirical investigations of parenting influences on the initiation of adolescent alcohol use. Previous research has evolved from two distinct traditions: examining a constellation of parenting constructs in the tradition of parenting style or examining unilateral parenting constructs. In the parenting style tradition, parents who employ authoritative parenting, a style that is both highly responsive and demanding, are less likely to have adolescents who use alcohol and other drugs (Baumrind, 1991; Lamborn, Mounts, Steinberg, \& Dornbusch, 1991). Yet studies of parenting style provide little insight into the processes whereby parents influence adolescent behavior (Belsky, Hertzog, \& Rovine, 1986).

The research tradition of examining unilateral parenting constructs has identified a number of parenting variables associated with adolescent substance use, including few parental restraints on adolescent peer orientation (Bogenschneider, Wu, Raffaelli, \& Tsay, in press; Brook, Whiteman. Gordon, \& Brook, 1988; Dishion \& Loeber, 1985; Kandel \& Andrews, 1987), insufficient parental responsiveness (Bogenschneider, $\mathrm{Wu}$, et al., in press; Kandel \& Andrews, 1987), and poor parental monitoring (Barnes \& Farrell, 1992; Barnes et al., 1994; Dishion \& Loeber, 1985; Patterson \& Stouthamer-Loeber, 1984; Richardson et al., 1989). Despite studies of a myriad of parental influences, few have focused on a unilateral variable - parental awareness of adolescent alcohol use - that, from a process perspective, may be fundamental to the effectiveness of other parenting variables. 


\section{Shortcomings of Previous Research}

Previous research on adolescent substance use has four shortcomings that will be addressed here. First, studies have not always distinguished between adolescent use of licit and illicit drugs (Baumrind, 1991; Brook, Whiteman, Gordon, \& Cohen, 1986a, 1986b), although licit drugs such as alcohol have different correlates than illicit drugs such as marijuana (Kandel \& Andrews, 1987; Kandel, Kessler, \& Margulies, 1978). Furthermore, studies have found little consistency between parents' awareness of adolescent use of one substance, such as alcohol, and their awareness of the use of other substances, such as tobacco or marijuana (Langhinrichsen et al., 1990; Ross et al., 1997). Thus, this study targets one substance, alcohol.

Second, studies have documented that the correlates of adolescent experimentation with substances or adolescents' occasional use of substances differ substantially from those of heavy use or abuse (Hawkins, Lishner, \& Catalano, 1987; Newcomb \& Bentler, 1989). Yet researchers often ignore distinctions between adolescent experimentation and regular use (Simons et al., 1988). Some studies have failed to specify the amount of alcohol consumption in their classification schemas (Baumrind, 1991; Brook et al., 1986a, 1986b). Others have lumped infrequent and frequent users into one category. For example, in some studies, adolescents who reported ever having used a substance were categorized as users (Barnes \& Welte, 1986; Kandel, 1986; Kandel \& Andrews, 1987; Kandel et al., 1978), and in other studies, adolescents who reported using a substance as seldom as once and as many as 11 times were combined into one category (Dishion \& Loeber, 1985). Many studies have used a continuous use scale, ranging from no use to frequent use (Hundleby \& Mercer, 1987), whereas other studies have used a cumulative Guttman scale, which assumes that a person who has used one substance (e $\mathrm{g}$. marijuana) also has used substances thought to precede it in the hierarchy (i.e. licit drugs, Brook et al., 1986a, 1986b; Kandel \& Andrews, 1987). Even though some adolescents experiment with alcohol without becoming regular users (Kandel et al., 1978), few studies have recognized this distinction and focused on adolescents who are regular drinkers. (For exceptions, see Barnes \& Farrell, 1992; Barnes et al., 1994). To avoid confounding experimentation with regular use, this study focuses only on adolescents who were using alcohol on a regular basis.
Third, scholars call for moving beyond direct connections between parenting practices and child outcomes to studying processes through which parenting practices influence child development (Maccoby, 1992). Although our knowledge of how parenting practices affect adolescent alcohol use is expanding (Barnes \& Farrell, 1992; Barnes et al., 1994; Brook et al., 1986b; Kandel, 1986; Kandel \& Andrews, 1987; Kandel et al., 1978), few studies have examined whether parents are aware of adolescent alcohol use and how this awareness affects other parent and adolescent behaviors.

Fourth, the studies that have examined parental awareness of adolescent alcohol use have found that parent perceptions typically are inaccurate. Thus, data from only parents are invalid for examining this issue. Importantly, the data in this study allow comparison of parent and adolescent reports.

\section{HYPOTHESIS}

This study addresses three sets of hypotheses. First, we predict that the majority of parents will be unaware of their adolescents' alcohol use and will be less likely to report this behavior for their own offspring than for their adolescents' close friends.

In the second set of hypotheses, we examine whether parental awareness of adolescent alcohol use is associated with other parent and adolescent behaviors. We predict that parents who are aware of their adolescents' alcohol use will have offspring who are less likely to report driving after drinking alcohol or riding with a teen driver who has been using alcohol. Also, we predict that parental awareness of adolescent alcohol use will moderate the effectiveness of such well-established correlates of adolescent alcohol use as parental monitoring, parental responsiveness, and adolescent peer orientation.

In the third set of hypotheses, we examine potential correlates of both mothers' and fathers' awareness of adolescent alcohol use. We hypothesize that 10 factors will differentiate parents who are aware and parents who are unaware of adolescent alcohol use: relative peer orientation, parent-adolescent discussion of risky behaviors, adolescent grade point average, parents' beliefs about alcohol use by their adolescents' close friends. parental monitoring, parental responsiveness, perceived parenting competence, parental worry about adolescent involvement in risky behaviors, parental values regarding 
adolescent alcohol use, and parents' perceived community support.

Poor parental monitoring has proven to be one of the most potent predictors of adolescent involvement in virtually any problem behavior (Barnes \& Farrell, 1992; Barnes et al., 1994; Bogenschneider, Wu, et al., in press; Dishion \& Loeber, 1985; Lamborn et al., 1991; Patterson \& Stouthamer-Loeber, 1984; Richardson et al., 1989; Wu, 1995). Extrapolating from this finding, we hypothesize that closer monitoring will be associated with heightened parental awareness of adolescents' use of alcohol. Parental responsiveness is also a correlate of adolescent alcohol use (Bogenschneider, Wu, et al., in press; Kandel \& Andrews, 1987). Therefore, we hypothesize that parents who are more responsive to their adolescents will be more privy to knowledge about their adolescents' use of alcohol.

Parents who perceived themselves as competent across a range of domains important to optimum parenting of adolescents had offspring who reported less substance use (Bogenschneider, Small, \& Tsay, 1997). Conceivably, parents' competence in other domains may have extended to awareness of their adolescents' use of alcohol. Studies also suggest that when parents have more connections to and assistance from others in the community, their adolescents report less substance use (Hawkins et al., 1987) Therefore, we predict that parents who perceive higher levels of community support will have more access to alternative sources of knowledge about their adolescents' use of alcohol.

Negative peer influence has emerged as the strongest predictor of adolescent substance use (Barnes et al., 1994, Dishion \& Loeber, 1985; Hawkins et al., 1992). Parents may be less knowledgeable about adolescent alcohol use if their children turn to peers more often than to parents for advice. Finally, academic failure has been associated with adolescent drug use (Dryfoos, 1990; Hawkins et al., 1987). We hypothesize that parents will be more alert to potential alcohol use when their adolescents perform poorly in school, a setting where parents are regularly informed of their children's progress.

One of the leading worries of parents of adolescents is that their children's involvement in deviant behaviors may jeopardize their safety (Pasley \& Gecas, 1984). Therefore, we hypothesize that parents who worry about their adolescents' involvement in risky behaviors will also be more aware of their adolescents' use of alcohol. Also, we predict that parents who believe that their adolescents' close friends drink alcohol will be more open to the possibility that their own children use alcohol. Permissive parental attitudes and values about adolescents' use of alcohol are strong predictors of adolescent substance use (Barnes \& Welte, 1986; Bogenschneider, Wu, et al., in press; Kandel \& Andrews, 1987). Thus, we predict that parents who are more accepting of adolescent alcohol use will be more open to the possibility of their adolescents' use. Finally, when parents express their views about the potential harmfulness of adolescent alcohol use, adolescents are less apt to initiate substance use (Kandel et al., 1978). We predict that parents who engage in more parent-adolescent discussions of risky behaviors will be more aware of adolescent alcohol use.

\section{MethoD}

\section{Plan of Analysis}

This study included only adolescents who reported regular alcohol use and their parents, an analytic strategy we chose for four reasons. First, this sub-sample offered the best test of the attention processes posited by social learning theory, which undergirds this study. Only adolescents who regularly use alcohol provide a behavior that their parents can attend to or be aware of. Second, in past research, the correlates of regular alcohol use were distinct from those of adolescent experimentation. Third, regular users of alcohol whose parents are unaware of their behavior have seldom been studied, yet they may be the subgroup of adolescents at greatest risk of the negative consequences of alcohol use. Finally, parental influences on adolescent initiation into the use of alcohol have been studied, with a lacunae of studies on what precautions parents can take to help adolescents avoid negative consequences after alcohol use begins.

\section{Sample and Procedures}

The subsample derives from a study of eighth to 12th graders $(n=1,227)$ and their parents $(n=1,176)$ from three school districts In urban, suburban, and rural settings in a single Midwestern county between December, 1994, and May, 1995.

Adolescents. Students were administered a 160-item questionnaire in their classrooms. In two schools, all students in the target grades were surveyed. In two larg- 
er schools, a representative subset of classrooms was selected by school guidance personnel, who took into account grade level and academic difficulty. Participation ranged from $84 \%$ to $96 \%$ across the schools. Overall, $88 \%$ of enrolled students participated. Only 10 students provided unusable data, yielding 1,227 students, none of whom were siblings.

Parents. Mothers and fathers were asked to complete a parallel 131-item mail survey. Envelopes were precoded with the same identification number assigned to the target child. Parents were asked to complete a survey for their oldest child (in schools where all students participated) or for a specific child (in schools where a subset of students took part). After two mailings, nonrespondents were contacted by telephone and encouraged to participate. A total of 1,306 parents returned a survey, yielding a response rate of $60 \%$ after adjusting for single-parent households and families who had moved during the study. Response rates ranged from $55 \%$ to $66 \%$ in the three school districts. Of the returned surveys, seven were blank, 45 had no matching data from the adolescent. and 78 were completed for the wrong child.

Matched sample. The matched sample consisted of 666 mother-adolescent dyads (324 boys and 342 girls) and 510 father-adolescent dyads (260 boys and 250 girls). Of the adolescents, $66 \%$ reported on both their mother and father. Even though all students were under the legal drinking age, $70 \%$ of the adolescents in the mother sample and $72 \%$ in the father sample reported using alcohol once or twice a year, $22 \%$ in the mother sample and $20 \%$ in the father sample reported using it from one to three times a month, and $8 \%$ in the mother sample and $8 \%$ in the father sample reported more frequent use. We differentiate between experimentation, defined in previous studies as trying a substance once or twice (Falco, 1988; Hawkins et al., 1992), and regular use, defined as using alcohol (i.e., beer, wine, wine coolers, or hard liquor) at least once a month in the past year. The description of the sample and measures derives from the subsample of regular alcohol users and their parents199 mother-adolescent dyads (30\% of the entire motherteen sample) and 144 father-adolescent dyads (28\% of the entire father- teen sample).

Study sample. Based on adolescent reports, $89 \%$ of those in the mother sample and $92 \%$ in the father sample were
White. The rest were Hispanic, Black, Asian, or Native American. The average age was 16 years for students in both the mother and father samples, 43 years for mothers, and 45 years for fathers. Most adolescents lived in two-parent biological or adoptive families $(70 \%$ in the mother sample and $75 \%$ in the father sample). About $13 \%$ lived in stepfamilies and about $10 \%$ in single-parent families. About one fourth of the parents had a high school education or less; $29 \%$ of mothers and $39 \%$ of fathers had college degrees or more education. The majority of mothers (75\%) and fathers (94\%) were employed 32 hours or more per week.

\section{Measures}

The parent and adolescent questionnaires include a battery of items on family and peer relations, perceptions of the school and community, and adolescent involvement in positive and problematic behaviors. The response categories, means, standard deviations, and reliability coefficients for the mother and father samples are reported in Table 1.

Drinking and driving behaviors. Students reported how often they had driven a motorized vehicle after drinking alcohol and also how often they had ridden in a motorized vehicle with a teen driver who had been drinking alcohol. We first created a continuous variable by counting the number of both types of drinking and driving episodes for each adolescent. Due to the infrequency of these episodes, this variable was skewed (skewness statistic $=1.85$ in the mother sample and 2.04 in the father sample). This skewing was not too surprising. One third of the sample of regular alcohol users were under age 16, the legal driving age in the state where the data were collected, and all were under the legal drinking age of 21. To adjust for this skewing, we formed two categories, based on whether or not students had engaged in episodes of drinking and driving. Students who had not driven after drinking or had not ridden with a teen driver who had been drinking were categorized as not engaging in episodes of drinking and driving. Students who reported at least one instance of either driving after drinking or riding with a teen driver who had been drinking were categorized as engaging in episodes of drinking and driving (18\% of adolescents in the mother sample and $15 \%$ in the father sample). 


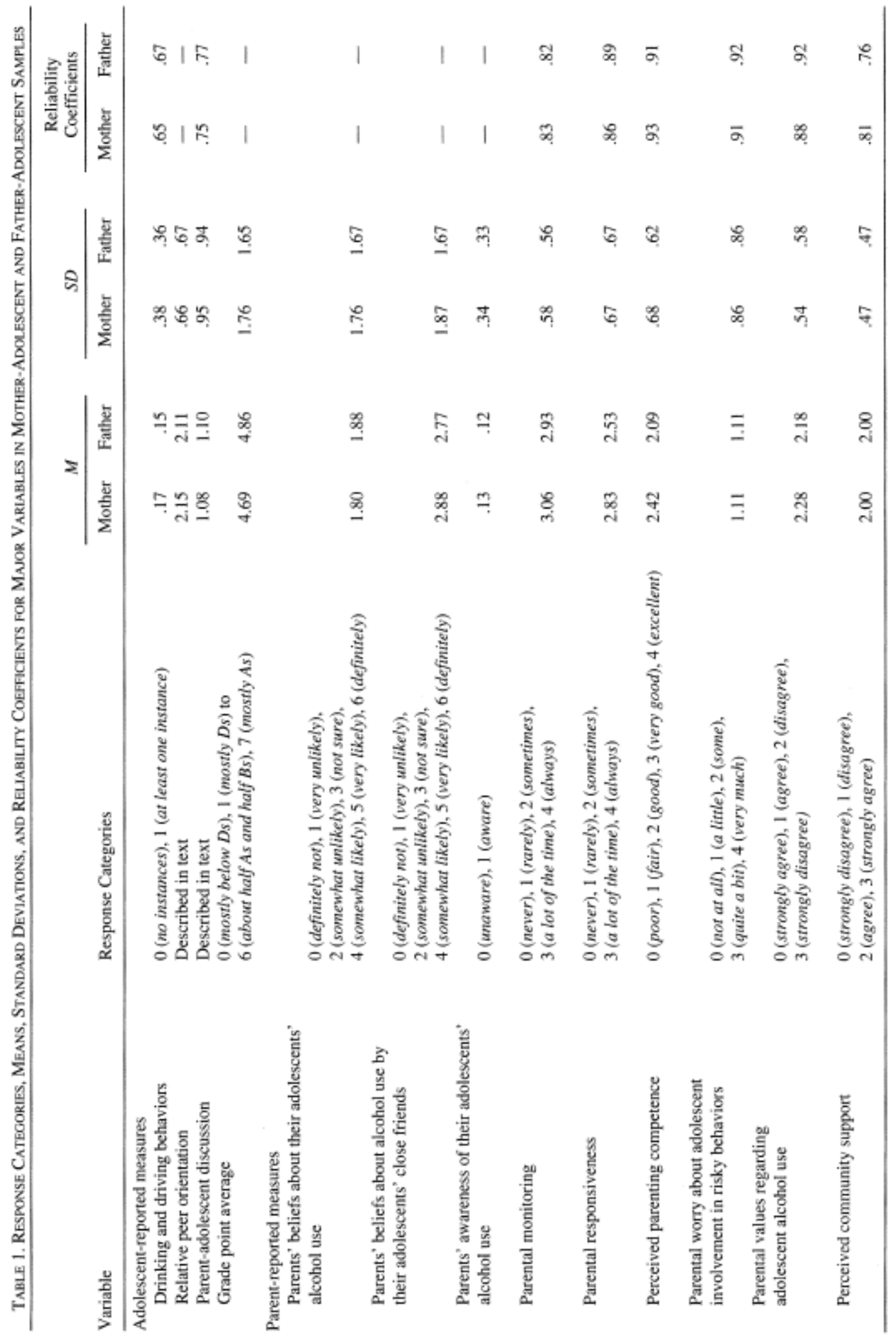


Relative peer orientation. Two questions were used jointly to classify adolescents' level of peer orientation relative to parent orientation (high, moderate, or low). These questions do not force adolescents to choose between peers and parents, but rather allow adolescents to indicate that they rely on both. In the first question, adolescents are asked to choose from a list of 10 alternatives the one person, if anyone, they would talk to if they were having a personal problem. Of these alternatives, three are parents or peers, six are non- parental adults or siblings, and one is "no one to talk with." In the second question, adolescents are asked if they have had at least one good talk with a parent about personal problems in the past year. Adolescents who chose to talk to friends and had never talked to a parent about personal problems in the past year were classified as 3, highly peer oriented. Adolescents who chose to talk to friends but also reported talking to a parent were classified as 2, moderately peer oriented. Adolescents who chose to turn first to a parent were classified as 1, low in peer orientation, regardless of whether or not they had talked to parents.

Of the adolescents who chose a response of either parent or peer on the first question, $30 \%$ in the mother sample and $28 \%$ in the father sample were classified as high in peer orientation, $55 \%$ in the mother sample and $54 \%$ in the father sample as moderate, and $15 \%$ in the mother sample and $17 \%$ in the father sample as low. About one fourth of the sample selected one of the seven other categories (e.g., teacher, coach, or school counselor; minister, priest, or rabbi; youth organization leader), which were irrelevant to the conceptualization of orientation to peers or parents. To examine whether these cases that were dropped from the analyses influenced the results, we compared students who selected a response of parent or peer with students who gave any other response to determine if their relationship to the dependent, independent, or control variables differed. The $t$ tests comparing parental awareness of alcohol use in these two groups of students were not significant in the sample of mothers, $t(197)=.10, p=.919$, or fathers, $t(142)=-.44, p=.659$. Similarly, in $t$ tests, none of the independent variables differed significantly between these two groups of students. Only one control variable reached or approached significance. Boys were more likely than girls to report turning to someone other than parents or peers when they had a personal problem, $t(197)=2.80, p=.006$ in the mother sample, and $t(142)=1.86, p=.064$ in the father sample. Child sex was significant in some analyses, but because it was not significant in the interaction tests or the discriminant analyses central to the study, this finding should not affect the primary results.

Parent-adolescent discussion of risky behaviors. Adolescents reported whether they had had at least one good talk with either or both parents in the previous year about (a) the risks of drinking or taking other drugs; (b) whether or not it is okay for teenagers to have sex; (c) birth control; and (d) the dangers or risks of getting AIDS, HIV, or other sexually transmitted diseases. Because mother-adolescent discussions are arguably a better predictor of mothers' awareness than are father-adolescent discussions, responses in the mother sample were coded 0 (no talk), 1 (talk with father only), 2 (talk with mother only), and 3 (talk with both parents). Because discussions with fathers are considered more important for fathers' awareness, responses in the father sample were coded 0 (no talk), 1 (talk with mother only), 2 (talk with father only), and 3 (talk with both parents). The four items were averaged to form an overall discussion score.

Grade point average. Students reported the average grade they received in courses at school.

Parents' beliefs about their adolescents' alcohol use. Parents responded to the question, "How likely is it that your child currently drinks alcohol?" in one of seven categories. (See Table 1.)

Parents' beliefs about alcohol use by their adolescents' close friends. Parents responded to the question, "How likely is it that your child's close friends currently drink alcohol?" in one of seven categories. (See Table 1.)

Parents' awareness of their adolescents' alcohol use. Previous studies have concluded that adolescent selfreports of alcohol use on anonymous or identifiable surveys are valid and reliable (Malvin \& Moskowitz, 1983; Mensch \& Kandel, 1988). Because this study included only adolescents who reported the regular use of alcohol, parents were classified as either unaware or aware of their adolescents' use of alcohol based on their response to a question regarding beliefs about the adolescent's alcohol use. Parents were coded unaware if they responded that the adolescent was somewhat, very, or definitely unlikely to be drinking alcohol. Parents were 
coded aware if they responded that the adolescent was somewhat, very, or definitely likely to be drinking alcohol or that they were not sure. The response, not sure, was classified in the aware category because parents typically underestimate adolescent alcohol use, and this uncertainty indicates some suspicion that the adolescent is using alcohol. (The percentages are reported in the results.)

Parental monitoring. Parental monitoring was assessed using six items adapted from a measure by Small and Kerns (1993). The scale assesses the extent to which parents know their adolescents' friends, the parents of their adolescents' friends, and the whereabouts of their adolescents. Sample items are: "When my child goes out at night, I know where he/she is," and "I know who my child's friends are." (See Table 1.)

Parental responsiveness. Parental responsiveness was assessed using a six-item measure adapted from Armsden and Greenberg's (1987) Inventory of Parent-Adolescent Attachment. As proposed by Maccoby and Martin (1983), the scale measures not only parental warmth expressed toward the child (e.g., "I tell my child that I love him/her), but also contingent responses and availability to the child (e.g., "My child and I just spend time talking with each other").

Perceived parenting competence. Parents' perception of competence in their parenting role was measured by a modified version (Bogenschneider et al., 1997) of the Cornell Parenting Activities List (Cochran \& Henderson, 1985; Small \& Riley, 1990). This 13-item scale asks parents to assess their performance on a range of parenting behaviors, including disciplining, supervising, and spending time with the child; understanding the child's moods; helping the child deal with personal problems and risky behaviors; and preparing the child for success.

Parental worry about adolescent involvement in risky behaviors. We asked parents how much they worry about their children's involvement in nine behaviors, including getting in trouble with the police, using alcohol or drugs too much, and getting pregnant or getting someone else pregnant. These questions were based on the work of Benson, Williams, and Johnson (1987).
Parental values regarding adolescent alcohol use. Measures of parental values regarding adolescent use of alcohol were adapted from questions developed by the Johnson Institute (Wilmes, 1991). Parents responded to six statements that assess whether they would make exceptions regarding adolescent alcohol use under various circumstances (e.g., "It is OK for my child to drink at family celebrations," "If my child did drink once in awhile, I wouldn't get upset").

Perceived community support. Parents' perception of community support was assessed using the average of four items, including whether their community is a good community in which to bring up children and whether people in their community know and care about each other.

\section{Results}

\section{Background Analyses of the Entire Sample}

First, descriptive data are presented for the entire sample to illustrate the proportion of the sample that met the criteria for this study. In $2 \times 2$ tables created separately for mothers and fathers, parent reports of the likelihood of adolescent drinking (i.e., unlikely vs. not sure or likely) were compared with adolescent reports (i.e., used alcohol at least once a month vs. did not). Among the mother- adolescent dyads, $66 \%$ fell into the quadrant in which adolescents reported no regular use and mothers reported it was unlikely their adolescents used alcohol. In only $4 \%$ of the cases did adolescents report no regular use and mothers report it was likely their children used alcohol. About a fifth of the entire sample (21\%) fell into the quadrant that we contend may be at greatest risk - adolescents who reported regular alcohol use and mothers who reported it was unlikely that their children used alcohol. Nine percent of adolescents reported regular alcohol use, and mothers also reported that it was likely that their children used alcohol. These latter two groups in which adolescents reported regular alcohol use yielded the sample of 199 mother-adolescent dyads that formed the basis of this analysis.

The distribution was almost identical among the father-adolescent dyads. Of the entire sample, $68 \%$ fell into the quadrant in which adolescents reported no regular use and fathers reported that use was unlikely. Only $3 \%$ of adolescents reported no regular use, and fathers 
reported that use was likely. About $19 \%$ of adolescents reported regular use, and fathers reported that use was unlikely. Nine percent of adolescents reported regular use, and fathers reported that it was likely. The latter two groups of adolescents who reported regular alcohol use yielded the sample of 144 father-adolescent dyads that formed the basis of this analysis.

\section{Parental Awareness of Adolescent Alcohol Use}

In preliminary analyses of the study sample, we computed zero-order correlations separately for mothers and fathers among the dependent. independent, and control variables. Intercorrelations were small to moderate, dispelling concerns about multicollinearity. In the mother sample, 9 of 136 correlation coefficients exceeded .35, and in the father sample, 11 of 136 exceeded .35 .

\section{Parental Awareness of Alcohol Use by Their Adoles- cents and Their Adolescents' Close Friends}

This first set of analyses confirmed our hypothesis that the majority of mothers and fathers would be unaware of their adolescents' alcohol use. Although all adolescents included in this study reported using alcohol at least once a month, only $29 \%$ of mothers were aware of their adolescents' alcohol use. Moreover, few aware mothers were definite when asked about the likelihood that their adolescents currently were using alcohol. Only 5\% responded "definitely": 4\%, "very likely"; and 6\%, "not sure." The largest group of aware mothers, 1552 , responded that their adolescents' alcohol use was "somewhat likely." Despite adolescents' reports of regular use of alcohol, the majority of mothers, $71 \%$, were unaware. Most were quite certain that their adolescents were not currently using alcohol. Specifically, $26 \%$ of the unaware mothers responded "definitely not," and $33 \%$ responded "very unlikely"; only $12 \%$ of the mothers responded that their adolescents' use was "somewhat unlikely."

We obtained similar results for fathers. Only $31 \%$ were aware that their adolescents were currently using alcohol. Few aware fathers were certain about their adolescents' use. Only 2\% responded "definitely"; $4 \%$, "very likely"; and 6\%, "not sure." The largest group of aware fathers, 19\%, responded that their adolescents' alcohol use was "somewhat likely." Despite adolescents' reports of regular alcohol use, $69 \%$ of fathers were unaware. The majority were quite certain that their adoles- cents did not currently drink alcohol. Specifically, 24\% of unaware fathers responded "definitely not," and $29 \%$ responded "very unlikely"; only $16 \%$ of the fathers responded "somewhat unlikely."

We compared parents' beliefs about their adolescents' alcohol use with their beliefs about alcohol use by the close friends of their adolescents in two categories (likely or not sure vs. unlikely). Chi-square analyses supported our hypothesis that mothers and fathers would be less likely to report alcohol use by their own adolescents than by the close friends of their adolescents, $\chi^{2}$ $(1, n=199)=75.43, p<.001$ for mothers. and $\chi^{2}(1, n=$ $144)=45.57, p<.001$ for fathers. The results were almost identical for mothers and fathers. Almost twice as many mothers and fathers, $56 \%$, reported that they were unsure or that it was likely that their adolescents' close friends drank alcohol, compared with $29 \%$ of mothers and $31 \%$ of fathers who reported that they were unsure or that it was likely their own adolescents drank alcohol. Almost all parents who believed that their own adolescents used alcohol reported believing that their adolescents' close friends drank alcohol $(98 \%$ for mothers and $93 \%$ for fathers). Only about half the parents who reported the likelihood of alcohol use among their adolescents' close friends, however, reported alcohol use by their own offspring (51\% for mothers and $52 \%$ for fathers). Finally, we examined whether these results were influenced by our decision to classify unsure parents as aware because parents were more apt to report being unsure of the alcohol use of close friends, compared with that of their own children. Even if the unsure parents were dropped from the frequencies, mothers were still almost twice as likely and fathers were $40 \%$ more likely to report alcohol use by their children's close friends than by their own children.

\section{Parental Awareness of Adolescent Alcohol Use as a Moderator of Other Parent and Peer Behaviors}

Next, we examined whether parental awareness of adolescent alcohol use was associated with adolescent and parent behaviors. First, logistic regressions examined whether aware parents were less likely than unaware parents to have offspring who reported episodes of drinking and driving, with controls for child's sex, child's age, parent's education, and family structure. Parental awareness was significantly related to risky, alcohol-related behaviors. Contrary to our hypotheses, however, we found a greater likelihood of reports of drink- 
ing and driving by adolescents of aware mothers than by adolescents of unaware mothers, $B=.34, \operatorname{Exp}(B)=1.40$, Wald $=10.36, p=.001$, and among aware fathers than among unaware fathers, $B=.24, \operatorname{Exp}(B)=1.27$, Wald $=3.79, p=.052$. Mothers and fathers who were aware of their adolescents' alcohol use had offspring who reported more frequent episodes of drinking and driving. Child sex was the only significant control variable in the father sample, $B=-.85, \operatorname{Exp}(B)=.43$, Wald $=3.70, p$ $=.054$; males reported more episodes of drinking and driving than females reported.

We also predicted that parental beliefs about adolescent alcohol use would moderate the influence of three well-established correlates of adolescent alcohol use. Specifically, we predicted that parental monitoring and responsiveness would be more effective in preventing episodes of drinking and driving among offspring of parents who were more apt to believe that their adolescents use alcohol. We predicted that negative peer influence would be less likely to elicit drinking and driving among offspring of parents who were more apt to believe that their adolescents use alcohol. To test the moderating effect of parental beliefs about adolescent alcohol use (Baron \& Kenney, 1986; Cohen \& Cohen, 1983), we computed interaction terms by multiplying mothers' beliefs about adolescent alcohol use by each independent variable (e.g., mothers' beliefs $\times$ parental responsiveness). This interaction was entered into one logistic regression analysis after controlling for the main effects of the independent variables, the moderator, and the control variables (i.e., child sex, child age, parent's education, and family structure). As recommended by Aiken and West (1991), we centered the predictors involved in the interaction. In regression analyses that include interactions, centering the variables minimizes the chances that multicollinearity will influence the estimation of the regression coefficients.

Among mothers, the only interaction that approached significance emerged between maternal responsiveness and mothers' beliefs about their adolescents' alcohol use, $B=-.47, \operatorname{Exp}(B)=62$, Wald $=3.56, p=.059$. This interaction indicates that there were differences among the slopes. Specifically, the relation between mothers' reports of responsiveness and their adolescents' reports of drinking and driving in the past month depended on mothers' beliefs about adolescent alcohol use. None of the control variables was significant. In follow-up logistic regressions, we examined whether the slopes representing aware and unaware mothers differed significantly from zero (Aiken \& West, 1991), as shown in Figure
Figlre 1, Moderating Erfect of Mothers' Awareness

OF ADOLESCENT AL.COHOL. USE ON THE RELATION BETWEEN MOTHER' RESPONSIVENESS AND Episodes of Adolescent Drinking and Driving

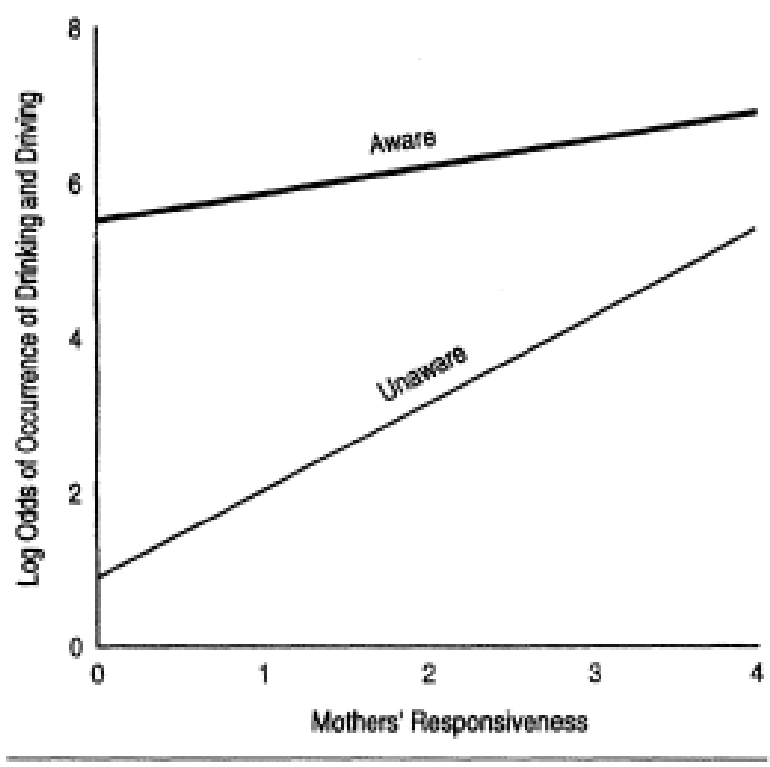

1. For mothers who were unaware of their adolescents' alcohol use, more maternal responsiveness was associated with a greater likelihood of the occurrence of episodes of drinking and driving, $B=1.13, \operatorname{Exp}(B)=3.10$, Wald $=4.67, p=.031$. For mothers who were aware that their adolescents used alcohol, however, the relationship between maternal responsiveness and the occurrence of drinking and driving did not differ significantly from zero. Of the control variables, only age approached significance among unaware mothers, with older adolescents reporting a greater likelihood of drinking and driving than younger adolescents, $B=.35, \operatorname{Exp}(B)=1.41$, Wald $=3.66, p=.056$.

The only significant interaction for fathers emerged between paternal responsiveness and fathers' beliefs about their adolescents' alcohol use, $B=-.62, \operatorname{Exp}(B)$ $=.54$, Wald $=4.90, p=, 027$. As indicated by the significant interaction, the slopes differed from each other. That is, the relation between fathers' responsiveness and adolescent reports of drinking and driving depended on fathers' beliefs about their adolescents' use of alcohol. None of the control variables reached conventional levels of significance. Following Aiken and West (1991), follow-up logistic regression analyses examined whether the slopes representing aware and unaware fathers differed significantly from zero. As shown in Figure 2, 
Figure 2. Moderating EFFect of Fathers' Awareness of Adolescent Alcohol Use on the Relation BETWEen FATHERS' ResponsivenESS AND EPISODES OF ADOLESCENT DRINKING AND DRIVING

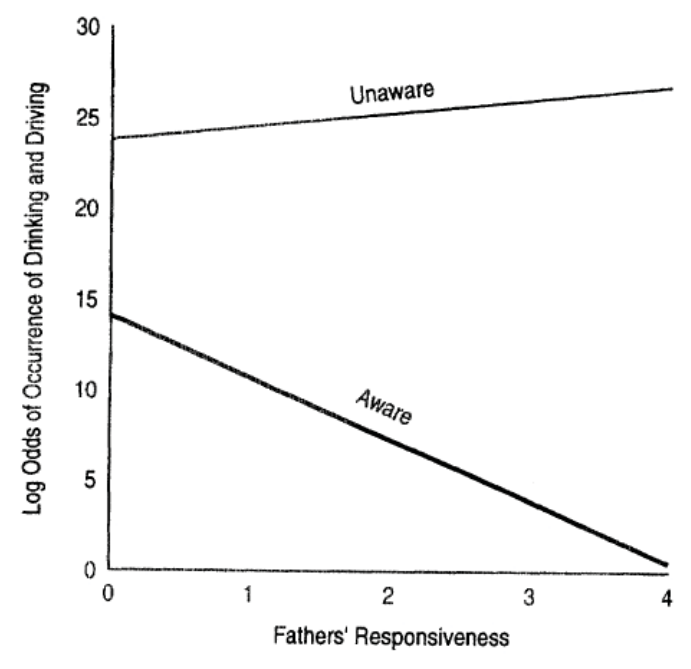

for fathers who were aware that their adolescents used alcohol, more responsiveness was associated with less likelihood of drinking and driving, $B=-3.43, \operatorname{Exp}(B)$ $=.03$, Wald $=5.56, p=.018$. For unaware fathers, however, responsiveness was not associated with episodes of adolescent drinking and driving. Of the control variables, only child's sex was significant among aware fathers, $B=-3.11, \operatorname{Exp}(B)=.045$, Wald $=3.73, p=.054$, with males reporting a greater likelihood of drinking and driving than females.

\section{Parent, Adolescent, and Community Correlates of Parental Awareness of Adolescent Alcohol Use}

Next, we examined parent, adolescent, and community correlates of parental awareness of adolescent alcohol use in discriminant function analyses conducted separately for mothers and fathers. The Wilks method was used to direct the progression of entry of the predictors, and the significance level of the $F$ value was set at .05 .

Table 2. Means and Standardized Discriminant Function CoefFicients for Mothers' AWareness OF AdOLESCENT AlCOHOL USE

\begin{tabular}{|c|c|c|c|c|}
\hline \multirow[b]{2}{*}{ Variable } & \multicolumn{2}{|c|}{ Means } & \multirow[b]{2}{*}{$\begin{array}{c}\text { Univariate } \\
F \\
(1,136)\end{array}$} & \multirow{2}{*}{$\begin{array}{c}\text { Standardized } \\
\text { Discriminant } \\
\text { Function } \\
\text { Coefficient }\end{array}$} \\
\hline & $\begin{array}{l}\text { Aware }^{a} \\
\text { Group }\end{array}$ & $\begin{array}{c}\text { Unaware }^{\mathrm{a}} \\
\text { Group }\end{array}$ & & \\
\hline \multicolumn{5}{|l|}{ Variables entered into the analysis } \\
\hline \multicolumn{5}{|l|}{ Parents' beliefs about alcohol use by their } \\
\hline adolescents' close friends ${ }^{\mathrm{b}}$ & 4.91 & 2.08 & $132.00^{* * * *}$ & $.51 * * *$ \\
\hline Parent-adolescent discussion ${ }^{\mathrm{c}}$ & 1.55 & .93 & $13.04 * * *$ & $.48 * * *$ \\
\hline Parental worry about adolescent risky behaviors ${ }^{\mathrm{d}}$ & 1.70 & .90 & $29.33 * * *$ & $.46 * * *$ \\
\hline \multicolumn{5}{|l|}{ Variables not entered into analysis } \\
\hline Parental monitoring ${ }^{\mathrm{e}}$ & 2.94 & 3.20 & $6.63^{* *} *$ & \\
\hline Grade point average $\mathrm{f}^{\mathrm{f}}$ & 4.35 & 5.11 & $6.05^{*}$ & \\
\hline $\mathrm{Sex}^{\mathrm{g}}$ & .67 & .50 & $3.92 *$ & \\
\hline Parental responsiveness & 2.71 & 2.94 & 3.28 & \\
\hline Perceived community support & 1.90 & 2.05 & 2.67 & \\
\hline Age & 6.26 & 5.97 & 1.32 & \\
\hline Perceived parenting competence & 2.32 & 2.46 & 1.32 & \\
\hline Mother's education & 3.95 & 4.18 & 1.00 & \\
\hline Family structure & .72 & 65 & 62 & \\
\hline Parental values regarding adolescent alcohol use & 2.26 & 2.33 & .43 & \\
\hline Relative peer orientation & 2.19 & 2.19 & .00 & \\
\hline \multicolumn{5}{|l|}{$\chi^{2}(3)=103.83^{* * *}$} \\
\hline \multicolumn{5}{|l|}{ Canonical $r=.73$} \\
\hline Eigenvalue $=1.16$ & & & & \\
\hline
\end{tabular}

aFor the aware group, $n=43$; for the unaware group, $n=95 .{ }^{\mathrm{b}} \mathrm{A}$ higher score indicates a greater likelihood that parents believe their child's close friends drink alcohol. ' $\mathrm{A}$ higher score means more discussion with parents. ${ }^{\mathrm{d}} \mathrm{A}$ higher score means more worry about the child's involvement in risky behaviors. ${ }^{\mathrm{e}} \mathrm{A}$ higher score means more parental monitoring. ${ }^{\mathrm{f}} \mathrm{A}$ higher score means a higher grade point average. ${ }^{\mathrm{g}} \mathrm{A}$ higher score means more females than males.

$* p<.05$. *** $p<.01$. **** $p<.001$. 
Table 3. Means and Standardized Discriminant Function Coefficients for FATHERS' AWARENESS OF ADOLESCENT ALCOHOL USE

\begin{tabular}{|c|c|c|c|c|}
\hline \multirow[b]{2}{*}{ Variable } & \multicolumn{2}{|c|}{ Means } & \multirow[b]{2}{*}{$\begin{array}{c}\text { Univariate } \\
F \\
(1,94)\end{array}$} & \multirow{2}{*}{$\begin{array}{c}\text { Standardized } \\
\text { Discriminant } \\
\text { Function } \\
\text { Coefficient }\end{array}$} \\
\hline & $\begin{array}{l}\text { Aware }{ }^{a} \\
\text { Group }\end{array}$ & $\begin{array}{c}\text { Unaware }^{a} \\
\text { Group }\end{array}$ & & \\
\hline \multicolumn{5}{|l|}{ Variables entered into the analysis } \\
\hline Parents' beliefs about alcohol use by their & & & & \\
\hline adolescents' close friends ${ }^{b}$ & 4.39 & 2.00 & $81.09 * * *$ & $.54 * * *$ \\
\hline Perceived community support ${ }^{\mathrm{c}}$ & 1.77 & 2.09 & $10.85^{* * *}$ & $.51 * * *$ \\
\hline Parental values regarding adolescent alcohol use $\mathrm{d}^{\mathrm{d}}$ & 1.95 & 2.27 & $6.85^{* *}$ & $.48 * * *$ \\
\hline \multicolumn{5}{|l|}{ Variables not entered into analysis } \\
\hline Parental worry about adolescent risky behaviors ${ }^{\mathrm{e}}$ & 1.58 & .92 & $14.05^{* * *}$ & \\
\hline Perceived parenting competence ${ }^{f}$ & 1.87 & 2.14 & $4.25^{*}$ & \\
\hline Parent-adolescent discussion & 1.17 & .82 & 3.36 & \\
\hline Age & 6.30 & 5.84 & 2.53 & \\
\hline Grade point average & 4.73 & 5.13 & 1.29 & \\
\hline Family structure & .79 & .68 & 1.18 & \\
\hline Parental responsiveness & 2.40 & 2.53 & .87 & \\
\hline Sex & .58 & .49 & .60 & \\
\hline Parental monitoring & 2.84 & 2.92 & .46 & \\
\hline Father's education & 4.39 & 4.56 & .35 & \\
\hline Relative peer orientation & 2.09 & 2.17 & .34 & \\
\hline \multicolumn{5}{|l|}{$\chi^{2}(3)=66.97 * * *$} \\
\hline \multicolumn{5}{|l|}{ Canonical $r=.72$} \\
\hline Eigenvalue $=1.06$ & & & & \\
\hline
\end{tabular}

aFor the aware group, $n=33$; for the unaware group, $n=63 .{ }^{\mathrm{b}} \mathrm{A}$ higher score indicates a greater likelihood that parents believe their child's close friends drink alcohol. ${ }^{\mathrm{c}} \mathrm{A}$ higher score means more perceived community support. ${ }^{\mathrm{d}} \mathrm{A}$ higher score indicates parental values that are more disapproving of adolescent alcohol use. ${ }^{\mathrm{e}} \mathrm{A}$ higher score means more worry about adolescent risky behaviors. ${ }^{\mathrm{f}} \mathrm{A}$ higher score means more perceived parenting competence.

$* p<.05$. ** $p<.01 . * * * p<.001$.

Tables 2 and 3 present the group means for all variables and the standardized discriminant function coefficients for variables that met the selection criteria and were entered in the stepwise analysis. The univariate $F$ value, equivalent to a $t$ test, examines whether the means in each group differ from one another. The discriminant function coefficients show the relative contribution of a particular variable when all other variables are taken into account.

As Table 2 shows, mothers who were aware that their adolescents used alcohol differed from those who were unaware on three variables of the 10 predictors and four controls. Compared with unaware mothers, aware mothers were more likely to believe that their adolescents' close friends drank alcohol, were more apt to engage in discussions of risky behaviors with their adolescents, and were more likely to worry about their adolescents' involvement in risky behaviors. The overall discriminant function was significant, $\chi^{2}(3, n=138)=103.83, p$ $=.001$. As indicated by the canonical correlation, it explained $73 \%$ of the variance. The classification analysis based on the discriminant function correctly predicted $84 \%$ of the cases.

As Table 3 shows, three variables discriminated fathers' awareness of adolescent alcohol use. Compared with unaware fathers, aware fathers were more likely to think that their children's close friends drank alcohol, were less likely to perceive their community as supportive, and were more apt to hold values less disapproving of adolescent drinking. The overall discriminant function was significant, $\chi^{2}(3, n=96)=66.97, p=.001$. As indicated by the canonical correlation, it explained $72 \%$ of the variance. The classification analysis correctly predicted 878 of the cases.

\section{DiscusSion}

The findings of this study replicate the results of a plethora of studies that attest to the potency of parents' active involvement in and connection to the lives of their children, even during the middle years of adolescence (Maccoby \& Martin, 1983; Steinberg, 1990). In 
accord with the predictions of a macrotheory like individuation-connectedness, the results provide a compelling example of parents who endanger their adolescents' development by abdicating attention to and participation in the lives of their offspring (Maccoby, 1992). This study also extends previous research by focusing on a variable that has received little empirical attention, parental awareness of adolescent alcohol use. Consistent with the predictions of a microtheory like social learning theory, parental awareness of adolescent use of alcohol moderates the relation between parental responsiveness and episodes of adolescent drinking and driving.

Our analysis focused on a subset of adolescents who were regularly using alcohol. Confirming our first set of hypotheses, only about one third of mothers (298) and fathers (314) were aware that their adolescents used alcohol. Awareness was defined as being unsure or believing that their adolescents' alcohol use was likely. When asked about alcohol use by their adolescents' close friends, however, over half (564) of mothers and fathers reported that they were unsure or it was likely. These parents seem to be saying. "Other teens drink, but not my kid."

Confidence in the finding that a minority of parents were aware of adolescent alcohol use is augmented by two methodological decisions that may overstate parental awareness. First, adolescents were classified as users of alcohol only if they reported regular use-drinking at least one to three times a month. For parents to be classified as aware of adolescent alcohol use, they were required to report only the likelihood that their child was currently drinking alcohol. Requiring parental acknowledgment of regular use would reduce further the proportion of aware parents. Second, the estimate is conservative because parents who reported being unsure of adolescent alcohol use were classified in the aware category. Removing the $6 \%$ of mothers and fathers who reported that they were "not sure" of their adolescents' use of alcohol would reduce the proportion of aware parents by about a fifth.

Our second set of hypotheses examined whether parental awareness of alcohol use matters. Contrary to our expectations, adolescent reports of driving after drinking or riding with a teen driver who had been drinking were more apt to occur among adolescents whose parents were aware than among those with parents who were unaware. Because it is not possible to determine the direction of effect with cross-section- al data, one plausible explanation is that episodes of drinking and driving serve to alert parents to the possibility that their offspring use alcohol. Consistent with our hypotheses and the predictions of social learning theory, parental awareness of adolescent use of alcohol appears to protect adolescents from negative consequences by moderating the relation between parental responsiveness and episodes of drinking and driving. Specifically, among aware fathers, higher levels of responsiveness were associated with less likelihood of drinking and driving, whereas among unaware fathers, responsiveness was not associated with drinking and driving. Among unaware mothers, higher responsiveness was associated with a greater likelihood of drinking and driving, whereas among aware mothers, responsiveness was not associated with drinking and driving. Although the specific pathways for mothers and fathers seem to differ, parents who were aware of adolescent alcohol use were available and responsive in ways that were associated with less likelihood of episodes of drinking and driving among offspring of fathers and were not associated with a greater likelihood of episodes of drinking and driving among offspring of mothers. These results replicate the findings of Patterson and associates (1992) that training parents to increase their knowledge of their children's whereabouts and activities did not reduce deviant behaviors unless this awareness was accompanied by appropriate parenting practices for reducing deviant behaviors or fostering prosocial responses.

Finally, we examined 10 correlates of parental awareness of adolescent alcohol use. Aware mothers were more likely to believe that their adolescents' close friends drank alcohol, more apt to engage in discussions of risky behaviors with their adolescents, and more likely to worry about their adolescents' involvement in risky behaviors. Aware fathers were more likely to believe that their adolescents' close friends drank alcohol, more apt to hold values that were less disapproving of adolescent alcohol use, and less likely to perceive their community as supportive. The direction of effect of community support was contrary to our expectations. Possibly, fathers who reported living in a supportive community with people who know and care about them may view the community more favorably and may be less likely to suspect that their adolescents use alcohol. Conversely, fathers who perceived less community support may be more vigilant about tracking their adolescents' alcohol use. 
The study advances our theoretical understanding of parent-adolescent relationships in two ways. First, more fully understanding parental influences on adolescent development may be facilitated by both macroand microtheories. Grand, all-encompassing macrotheories (e.g., individuation-connectedness) describe the importance of an ongoing connection between the parent and the increasingly autonomous adolescent, whereas microtheories (e.g., social learning) define the specific pathways though which parenting practices translate into adolescent outcomes.

Second, consistent with Bandura's (1977) conceptualization of social learning theory, contingent parenting depends, in part, on the attention parents grant to their adolescents, specifically the processes through which parents observe, become aware of, and respond to their adolescents' daily behavior. Although parental awareness may be necessary for protecting adolescents from risky behaviors, awareness in and of itself is not sufficient. For example, aware parents had adolescents who were more apt to report episodes of drinking and driving. Yet only when fathers were aware did responsiveness translate into a reduced likelihood of risky drinking and driving on the part of their offspring. Among mothers, responsiveness, although widely considered optimal, may actually have adverse consequences if mothers are not aware of their adolescents' involvement in potentially risky behaviors.

Methodologically, we argue that more finely tuned analyses are needed that specify the type of substance, whether the adolescent experiments with substance use or is a regular user, and whether parents are aware of adolescent use. Because our findings suggest that most parents are unaware of adolescent alcohol use, an obvious methodological implication is that studying parents who report being unaware that their adolescents use alcohol is meaningless without data from adolescents to assess the accuracy of parental beliefs.

Pragmatically, the results suggest the importance of taking steps to elevate parental awareness of adolescent drinking. One strategy for parent educators may be teaching the correlates identified in this study. With the community's permission, we also have used parent education newsletters to disseminate the results of local community surveys that include adolescents' reports of alcohol use and parents' beliefs about adolescent use. Parents who read these newsletters were significantly more aware of adolescent drinking than those who did not read them (Bogenschneider \& Stone, 1997).
This study has several limitations. First, given the exploratory nature of the findings, replication clearly is needed with better measures, varied outcomes, and racially diverse samples. Second, both parent and adolescent reports are subject to bias. Because previous research suggests adolescents accurately report alcohol use, adolescent reports are used as the baseline in this study. Yet this does not negate the need for further research to disentangle how accurately parents and adolescents report adolescents' use of alcohol. Because parents typically underestimate adolescent alcohol use, an interesting question is whether the $4 \%$ of mothers and $3 \%$ of fathers who reported adolescent alcohol use when their adolescents reported none are actually instances of adolescent underreporting. Third, the cross-sectional nature of the data renders it impossible to determine the direction of effects, thereby limiting our confidence in interpreting the results. We imply that variables like parental worrying and discussion lead to parents' awareness that their adolescents use alcohol, but conceivably the reverse could be true - that parents' awareness leads to heightened worry and more discussions with their teens. Finally, our interpretation of the findings implies that parental awareness is primarily the prerogative of parents, yet parents' knowledge of their adolescents' alcohol use may be influenced by children's openness to socialization (Bogenschneider et al., 1997; Darling \& Steinberg, 1993; Maccoby \& Martin, 1983). For example, parents can be literally "fired" by adolescents who deliberately conceal their behavior (Ginott. 1965), making it difficult for even attentive parents to stay abreast of their adolescents' activities and to secure the information necessary to guide their adolescents' decision making.

If engaging in risky behaviors is one way adolescents test limits and demonstrate independence, it may not be possible to dissuade all adolescents from engaging in risky behaviors such as alcohol use (Baumrind, 1987; Irwin \& Millstein, 1986). Yet it is imperative to identify the processes through which parents can minimize the life-threatening consequences of such risky behaviors. Variables such as parental monitoring, examined in previous studies, and parental awareness of adolescent alcohol use, examined in this study, imply that some parenting practices may be prerequisites for the effectiveness of others. 


\section{Note}

The authors thank the parents and students who participated in this study, County Extension educators Peg Thomas and Ruth Schriefer for their contributions to data collection, and the faculty and staff from three school districts for their cooperation and support. The assistance of Elizabeth Ragsdale and Meg Wall-Wild in manuscript preparation is gratefully acknowledged. This research was made possible through financial support provided to the first author by the U.S. Department of Agriculture-Extension Service and Land O'Lakes. An earlier version of this article was presented at the 1995 annual meeting of the National Council on Family Relations, Portland, Oregon.

\section{REFERENCES}

Aiken, L. S., \& West, S. G. (1991). Multiple regression: Testing and interpreting interactions. Newbury Park, CA: Sage.

Armsden, G., \& Greenberg, M. T. (1987). Inventory of parent and peer attachment: Individual differences in their relationship to psychological well-being in adolescence. Journal of Youth and Adolescence, 16, 427-453.

Bandura, A. (1977). Social learning theory. Englewood Cliffs, NJ: Prentice-Hall.

Barnes, G. M., \& Farrell, M. P. (1992). Parental support and control as predictors of adolescent drinking, delinquency, and related problem behaviors. Journal of Marriage and the Family, 54, 763-776.

Barnes, G. M., Farrell, M. P., \& Banerjee, S. (1994). Family influences on alcohol abuse and other problem behaviors among Black and White adolescents in a general population sample. Journal of Research on Adolescence, 4, 183-201.

Barnes, G. M., \& Welte, J. W. (1986). Patterns and predictors of alcohol use among 7-12th grade students in New York State. Journal of Studies on Alcohol, 47, 53-61.

Baron, R. M., \& Kenny, D. A. (1986). The moderator/mediator variable distinction in social psychological research: Conceptual, strategic, and statistical considerations. Journal of Personality and Social Psychology, 51, 11731182.

Baumrind, D. (1987). A developmental perspective on adolescent risk taking in contemporary America. In C. E. Irwin, Jr. (Ed.). Adolescent social behavior and health. New directions for child development (No. 37, pp. 93-125). San Francisco: Jossey-Bass.

Baumrind, D. (1991). The influence of parenting style on adolescent competence and substance abuse. Journal of Early Adolescence, 11, 56-95.

Belsky, J., Hertzog, C., \& Rovine, M. (1986). Causal analyses of multiple determinants of parenting: Empirical and methodological advances. In M. Lamb, A. Brown, \& B. Rugoff (Eds.) Advances in developmental psychology, Vol. 4 (pp. 153-202). Hillsdale, NJ: Erlbaum.

Benson, P., Williams, D., \& Johnson, A. (1987). The quick-sil- ver years: The hopes and fears of early adolescence. San Francisco: Harper \& Row.

Blechman, E. A. (1980). Family problem-solving training. The American Journal of Family Therapy, 8, 3-21.

Blos, P. (1979). The adolescent passage: Developmental issues. New York: Guildford Press.

Bogenschneider, K., Small, S., \& Tsay, J. (1997). A contextual analysis of parental competence among parents of adolescents. Journal of Marriage and the Family, 59, 345-362.

Bogenschneider, K., \& Stone, M. (1997). Delivering parent education to low- and high-risk parents of adolescents via age-paced newsletters. Family Relations, 46, 123-134.

Bogenschneider, K., Tsay, J., \& Wu, C-r. (1996). A report of the findings of the Tapping into Parenting (TIP) surveys in 12 Wisconsin communities. Madison: University of Wisconsin.

Bogenschneider, K., Wu, M-y., Raffaelli, M., \& Tsay, J. (in press). Parent influences on adolescent peer orientation and substance use: The interface of parenting practices and values. Child Development.

Brook, J. S., Whiteman, M., Gordon, A. S., \& Brook, D. W. (1988). The role of older brothers in younger brothers' drug use viewed in the context of parent and peer influences. The Journal of Genetic Psychology, 151, 59-75.

Brook, J. S., Whiteman, M., Gordon, A. S., \& Cohen, P. (1986a). Dynamics of childhood and adolescent personality traits and adolescent drug use. Developmental Psychology, 22, 403-414.

Brook, J. S., Whiteman, M., Gordon, A. S., \& Cohen, P. (1986b). Some models and mechanisms for explaining the impact of maternal and adolescent characteristics on adolescent stage of drug use. Developmental Psychology, 22, 460-467.

Cochran, M., \& Henderson, C. R. (1985). Comparative ecology of human development project: Wave II instruments. Ithaca, NY: Cornell University.

Cohen, J., \& Cohen, P. (1983). Applied multiple regression/ correlation analysis for the behavioral sciences (2nd ed.). Hillsdale, NJ: Erlbaum.

Conger, R. D. (1976). Social control and social learning models of delinquent behavior: A synthesis. Criminology, 14, $17-40$.

Cooper, C. R., \& Cooper, R. G. (1992). Links between adolescents' relationships with their parents and peers: Models, evidence, and mechanisms. In R. D. Parke \& G. W. Ladd (Eds.), Family-peer relationships: Modes of linkage. Hillsdale, NJ: Erlbaum.

Darling, N., \& Steinberg, L. (1993). Parenting style as context: An integrative model. Psychological Bulletin, 113, 487-496.

Dielman, T. E., Leech, S. L., \& Loveland-Cherry, C. (1995). Parents' and children's reports of parenting practices and parent and child alcohol use. Drugs and Society, 8, 83101.

Dishion, T. J., \& Loeber, R. (1985). Adolescent marijuana and alcohol use: The role of parents and peers revisited. 
American Journal of Drug and Alcohol Abuse, 11, 11-25.

Dryfoos. J. G. (1990). Adolescents at risk: Prevalence and prevention. New York: Oxford University Press.

Ellickson, P. L. (1992). Helping urban teenagers avoid highrisk behavior: What we've learned from prevention research. In J. B. Steinberg, D. W. Lyon, \& M. E. Vaiana (Eds.), Urban America: Policy choices for Los Angeles and the nation. Santa Monica, CA: RAND.

Falco, M. (1988). Preventing abuse of drugs, alcohol and tobacco by adolescents. New York: Carnegie Council on Adolescent Development.

Freud, A. (1958). Adolescence. Psychoanalytic Study of the Child, 13, 255-278.

Ginott, H. G. (1965). Between parent and child: New solutions to old problems. New York: Macmillan.

Hawkins, J. D., Catalano, R. D., \& Miller. J. Y. (1992). Risk and protective factors for alcohol and other drug problems in adolescence and early adulthood: Implications for substance abuse prevention. Psychological Bulletin. 112, 64-105.

Hawkins, J. D., Lishner, D. M., \& Catalano, R. F. (1987). Childhood predictors and the prevention of adolescent substance abuse (National Institute on Drug Abuse Monograph 56. DHHS Publication No. ADM 87-1335, pp. 75-126). Washington, DC: U.S. Government Printing Office.

Higgins. P. S. (1988). The prevention of drug abuse among teenagers: A literature review. St. Paul. MN: Amherst H. Wilder Foundation.

Hundleby, J. D., \& Mercer. C. W. (1987). Family and friends as social environments and their relationship to young adolescents' use of alcohol, tobacco, and marijuana. Journal of Marriage and the Family, 49, 151-164.

Irwin, C. E., Jr., \& Millstein, S. G. (1986). Biopsychosocia1 correlates of risk-taking behaviors during adolescence: Can the physician intervene? Journal of Adolescent Health Care, 7, 82S-96S.

Johnston, L. D., O’Malley. P. M., \& Bachman, J. G. (1996). National survey results in drug use from the Monitoring the Future Study, 1975-1996. Vol. I. Secondary school students (National Institute for Drug Abuse, NIH Publication No. 96-4139). Washington, DC: U.S. Government Printing Office.

Kandel, D. B. (1986). Processes of peer influences in adolescence. In R. K. Silbereisen, K. Eyferth, \& G. Rudinger (Eds.), Development as action in context: Problem behavior and normal youth development (pp. 203-228), New York: Springer-Verlag.

Kandel, D. B., \& Andrews, K. (1987). Processes of adolescent socialization by parents and peers. The International Journal of the Addictions, 22, 319-342.

Kandel, D. B., Kessler. R. C., \& Margulies, R. Z. (1978). Antecedents of adolescent initiation into stages of drug use: A developmental analysis. In D. B. Kandel (Ed.), Longitudinal research and drug use: Empirical findings and methodological issues (pp. 73-98). Washington, DC:
Hemisphere.

Kandel, D. B., Single. E., \& Kessler, R. C. (1976). The epidemiology of drug use among New York State high school students: Distribution, trends, and change in the rate of use. American Journal of Public Health, 66, 43-53.

Lamborn, S. D., Mounts, N. S., Steinberg, L., \& Dornbusch, S. D. (1991). Patterns of competence and adjustment among adolescents from authoritative, authoritarian, indulgent and neglectful families. Child Development, 62, 1049-1065.

Langhinrichsen, J., Lichtenstein, E., Seeley, J. R., Hops, H., Ary, D. V., Tildesley, E., \& Andrews, J. (1990). Parentadolescent congruence for adolescent substance use. Journal of Youth and Adolescence, 19, 623-635.

Levy, S. R., Lampman, C., Handler. A., Flay, B. R., \& Weeks, K. (1993). Young adolescent attitudes toward sex and substance abuse: Implications for AIDS prevention. AIDS Education and Prevention, 5, 340-351.

Maccoby, E. E. (1984). Socialization and developmental change. Child Development, 55, 317-328.

Maccoby, E. E. (1992). The role of parents in the socialization of children: An historical overview. Developmental Psychology, 28, 1006-1017.

Maccoby, E. E., \& Martin, J. A. (1983). Socialization in the context of family: Parent-child interaction. In P. H. Mussen (Series Ed.) \& E. M. Hetherington (Vol. Ed.), Handbook of child psychology: Vol. 4. Socialization, personality, and social development (4th ed., pp. 1-101). New York: Wiley.

Malvin, J. H., \& Moskowitz, J. M. (1983). Anonymous versus identifiable self-reports of adolescents drug attitudes. intentions. and use. Public Opinion Quarterly, 47, 557566.

Mensch, R. S., \& Kandel, D. B. (1988). Underreporting of substance use in a national longitudinal youth cohort: Individual and interviewer effects. Public Opinion Quarter$l y, 52,100-124$.

Muuss, R. E. (1988). Theories of adolescence (5th ed.). New York: Random House.

Newcomb, M. D., \& Bentler, P. M. (1989). Substance use and abuse among children and teenagers. American Psychologist, 44, 242-248.

Pasley, K., \& Gecas, V. (1984, March). Stresses and satisfactions of the parental role. The Personnel and Guidance Journal, 400-404.

Patterson, G. R. (1975). Families: Applications of social learning to family life (5th ed.), Champaign, IL: Research Press.

Patterson, G. R. (1986). Performance models for antisocial boys. American Psychologist, 41, 432-444.

Patterson, G. R., De Baryshe, B. D., \& Ramsey, E. (1989). A developmental perspective on antisocial behavior. American Psychologist, 44, 329-335.

Patterson, G. R., \& Gullion, M. E. (1968). Living with children: New methods for parents and teachers. Champaign, IL: Research Press. 
Patterson, G. R., Reid, J. B., \& Dishion, T. J. (1992). A social interactional approach: Vol. 4. Antisocial boys. Eugene, OR: Castalia.

Patterson, G. R., \& Stouthamer-Loeber, M. (1984). The correlation of family management practices and delinquencies. Child Development, 55, 1299-1307.

Reilly, D. M. (1976). Family factors in the etiology and treatment of youthful drug abuse. Family Therapy, 2, 149171.

Richardson, J. L., Dwyer, K., McGuigan, K., Hansen, W. R., Dent, D., Johnson, C. A,. Sussman, S. Y., Brannon, R., \& Phil, B. F. (1989). Substance use among eighth grade students who take care of themselves after school. Pediatrics, 84, 556-566.

Robins, L. N., \& Przybeck, T. R. (1987). Age of onset of drug use as a factor in drug and other disorders (National Institute on Drug Abuse Monograph 56, DHHS Publication No. ADM 87-1335, pp. 178-192). Washington, DC: U.S. Government Printing Office.

Ross, L. T., Leech, S. L., \& Loveland-Cherry, C. (1997. April) Parenting practices and substance use: Child and parent agreement. Poster session presented at the annual meeting of the Society for Research in Child Development. Washington. DC.

Simons, R. L., Conger, R. D., \& Whitbeck, L. B. (1988). A multistage social learning model of the influences of family and peers upon adolescent substance abuse. The Journal of Drug Issues, 18, 293-315.

Small, S. A., \& Kerns, D. (1993). Unwanted sexual activity among peers during early and middle adolescence: Inci- dence and risk factors. Journal of Marriage and the Family, 55, 941-952.

Small, S. A., \& Riley, D. (1990). Toward a multidimensional assessment of work spillover into family life. Journal of Marriage and the Family, 52, 51-61.

Smart, L. S., Chibucos, T. R., \& Didier, L. A. (1990). Adolescent substance use and perceived family functioning. Journal of Family Issues, 11, 208-227.

Steinberg, L. (1990). Autonomy, conflict, and harmony in the family relationship. In S. Feldman \& G. Elliot (Eds.). At the threshold: The developing adolescent. Cambridge, MA: Harvard University Press.

U.S. Department of Health and Human Services. (1995a). National drunk and drugged driving prevention month: December 1995. Morbidity and Mortality Weekly Report, 44, 869 .

U.S. Department of Health and Human Services. (1995b). Update: Alcohol-related traffic crashes and fatalities among youth and young adults-United States, 1982-1994. Morbidity and Mortality Weekly Report, 44, 869-874.

Wilmes, D. (1991, June 4-6). Blame parents for teen drinking? USA Today, p. 11A.

Wu, M-y. (1995). Reconceptualizing parental control and its relationship to adolescent academic success and involvement in fighting behavior. Unpublished doctoral dissertation. University of Wisconsin, Madison.

Youniss, J., \& Smollar, J. (1985). Adolescents' relations with mothers, fathers, and friends. Chicago: University of Chicago Press. 